
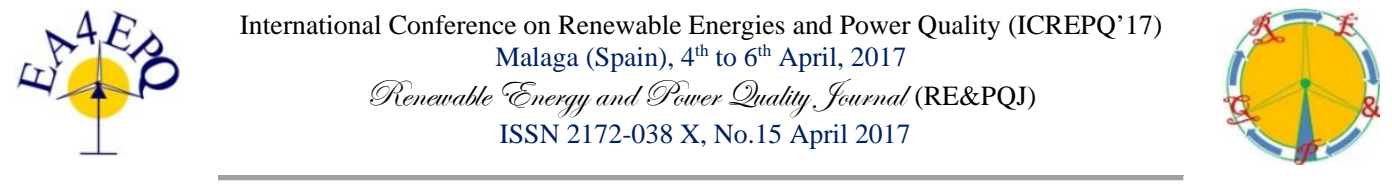

\title{
Electromagnetic evaluation of an in-wheel double rotor axial-flux switched reluctance motor for electric traction
}

\author{
P.Andrada, E.Martínez, M.Torrent, B.Blanqué \\ GAECE, DEE, EPSEVG. \\ Universitat Politècnica de Catalunya UPC-BARCELONATECH, \\ Avinguda Victor Balaguer 1, 08800, Vilanova i la Geltrú, Spain \\ Phone:34 938967732 \\ Fax:34 938967700 \\ e.mail; pere.andrada@upc.edu
}

\begin{abstract}
In this paper, a novel in-wheel double rotor axialflux switched reluctance motor for electric traction is presented. The proposed double rotor axial-flux switched reluctance motor has a particular disposition of the stator and rotor poles that provides short flux path without flux reversal. The ferromagnetic pieces of the stator and the rotor are built using soft magnetic composites. Electromagnetic analysis is performed using three dimensional finite element analyses, 3D FEA. Matlab-Simulink simulation coupled with the results of finite element analysis proves that the proposed motor drive is suitable for the propulsion of a given E-scooter.
\end{abstract}

\section{Key words}

FEM analysis, switched reluctance motor, axial-flux switched reluctance motor, traction motor.

\section{Introduction}

In E-traction the use of in-wheel motors (or hub motors) for direct traction have some advantages. Nowadays the most usual in-wheel motors are brushless d.c. motors or permanent magnet synchronous motors with external rotor. Nevertheless, switched reluctance motors due to the absence of permanent magnets and its rugged construction point as a promising alternative.

Usually the rotary switched reluctance machines (SRM) are radial flux machines where the air gap flux is mainly in the radial direction relative to the axis of rotation. This type of SRM, usually have a cylindrical shape with a stator and a rotor that can be internal, the most common disposition, or external. A less usual rotary switched reluctance machine is the axial flux SRM in which the air gap flux is mostly parallel to the axis of rotation. The stator and rotor are in parallel plates arranged perpendicular to the axis of rotation.
Some studies carried out in axial flux switched reluctance motors, demonstrate that with this type of machine is possible to obtain higher torque density than in radial flux switched reluctance machines. These better features of the axial flux switched reluctance machine machine are due to the increase of the air-gap area, which depend on the diameter of the machine, whereas in the radial type machine air-gap area depend on the machine length. Although a first axial-flux variable reluctance motor was reported by Unnewher and Koch, as early as 1973 [1]. Recently, some authors have made important contributions to the development of axial-flux switched reluctance machines. Arihara et al. have presented the basic design methodology for the axial counterpart of the classic rotary SRM [2]. Murakami et al, have studied the optimization of an axial-flux 18/12 SRM [3]. Madahvan et al. have contributed to the development to the axial counterpart of rotor segmented SRM in a machine with two rotor and a stator with a toroidal type winding [4]. Labak et al. have proposed a novel multiphase pancake shaped SRM with a stator composed of a series of Ccores, each with an individual wound coil, perpendicularly disposed to a rotor made with aluminum in which a suitable number of cubes, the rotor poles, of high permeability material have been added. In this machine, the torque production is due to the tendency of any of these cubes to align with the two poles of an energized Ccore [5]. Some authors have exposed the manufacturing problems of these machines and proposed to use different materials for building its magnetic circuit as grain oriented electrical steel, Ma et al. [6]; soft magnetic composite, Kellerer et al. [7]; sintered lamellar soft magnetic composite, Lambert et al. [8]. Recently, Andrada et al. [9] have presented a new axial flux-switched reluctance machine (AFSRM) with a particular distribution of stator and rotor poles that results in short flux paths without flux 
Table 1- Relationships of the stator poles, rotor poles and the angles between them depending on the number of phases and multiplicity

\begin{tabular}{|l|c|}
\hline & RELATIONSHIPS \\
\hline Number of phases & $m$ \\
\hline Multiplicity (number of working stator pole pairs) & $Z=k m$ \\
\hline Number of double electromagnets $(Z)$ & $N_{S}=2 Z=2 \mathrm{~km}$ \\
\hline Number of stator poles $\left(N_{S}\right)$ & $N_{R}=k(2 \mathrm{~m}-1)$ \\
\hline Number of rotor poles $\left(N_{R}\right)$ & $\gamma=\frac{360^{\circ}}{Z}$ \\
\hline $\begin{array}{l}\text { Angle between axes of consecutive double } \\
\text { electromagnets }(\gamma)\end{array}$ & $\alpha=\frac{360^{\circ}}{N_{R}}$ \\
\hline Angle between rotor poles $(\alpha)$ & $\delta=\gamma-\alpha=\frac{360^{\circ}\left(N_{R}-(k m)\right)}{k m N_{R}}$ \\
\hline $\begin{array}{l}\text { Angle between axes of stator poles of the two } \\
\text { consecutive double electromagnets }(\delta)\end{array}$ & \\
\hline
\end{tabular}

reversal, specially intended for the propulsion of Escooters. In this paper, after an extended description of this type of machine a 3D FEM simulation of an in wheel axial-flux switched reluctance motor is performed.

\section{Description of the proposed AFSRM}

The simplest embodiment of the proposed axial flux switched reluctance motor, with $m=3$ and $k=1$, is constituted by a stator comprising six stator poles distributed non-equidistantly along a ferromagnetic plate nailed to a hollow shaft. Electromagnet coils wound on said stator poles; and a rotor comprising five rotor poles distributed equidistantly along a second ferromagnetic plate on a rotor plane orthogonal to a rotation axis, parallel to said stator plane and separated therefrom by an air- gap. The cross section of the stator and rotor poles can be of different shapes: round, triangular or trapezoidal. The coils of the stator are disposed in such a way that the coils connected in series forms a double electromagnet and, at same time, one phase of the motor. In order to clarify the constitution of the motor in Fig. 1 a schematic side view of the AFSRM is shown while Fig. 2 and Fig 3 are front views of the stator and rotor, showing in both cases the angles that define the disposition of the poles.

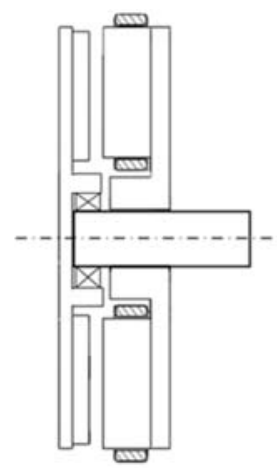

Fig. 1. Schematic side view of the AFSRM

Once a phase is activated, a flow path is created which embraces the two adjacent stator poles in which the excited coils are located and their ferromagnetic plate of support, as well as two rotor poles and their ferromagnetic back plate, trying to align the rotor poles with the stator poles. Flux path that in comparison with those of the conventional AFSRM that embraces diametrically disposed stator poles, is short and does not undergo flux reversal.

The number of double electromagnets, $Z$, the number of stator poles, $N_{S}$, the number of rotor poles, $N_{R}$, besides the angles between poles, are related to the number of phases, $m$. and the multiplicity, $k$, by the relationships collected in Table I. These relationships applied machines with three or four phases with different values of multiplicity are shown in Table II.

The three-phase motor with single multiplicity has as main drawback the significative presence of axial forces. Therefore the easiest alternative that solves this inconvenience is the three-phase motor with multiplicity 2, option marked in bold in table II. In this case the stator is sandwiched by the two rotors, see Fig. 4.

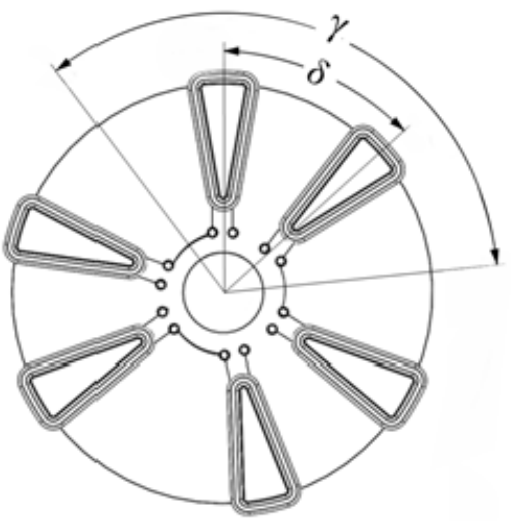

Fig.2. Front view of the AFSRM

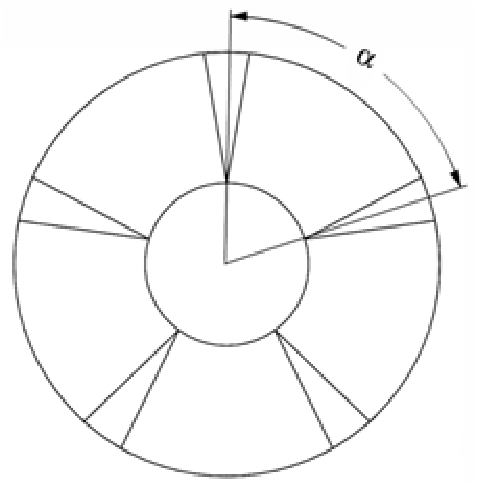

Fig.3. Front view of the rotor of the AFSRM 
Table II - Examples of number of electromagnets, number of stator rotor poles and angles between them for three and four phases AFSRM

\begin{tabular}{|c|c|c|c|c|c|c|c|}
\hline $\mathbf{k}$ & $\mathbf{m}$ & $\mathbf{Z}$ & $\mathbf{N}_{\mathbf{s}}$ & $\mathbf{N}_{\mathbf{R}}$ & $\boldsymbol{\alpha}\left(^{\circ}\right)$ & $\mathbf{\mathbf { } ^ { \circ } )}$ & $\mathbf{\delta}\left({ }^{\circ}\right)$ \\
\hline 1 & 3 & 3 & 6 & 5 & 72,00 & 120,00 & 48,00 \\
\hline $\mathbf{2}$ & $\mathbf{3}$ & $\mathbf{6}$ & $\mathbf{1 2}$ & $\mathbf{1 0}$ & $\mathbf{3 6 , 0 0}$ & $\mathbf{6 0 , 0 0}$ & $\mathbf{2 4 , 0 0}$ \\
\hline 3 & 3 & 9 & 18 & 16 & 22,50 & 40,00 & 17,50 \\
\hline 4 & 3 & 12 & 24 & 22 & 16,36 & 30,00 & 13,64 \\
\hline 1 & 4 & 4 & 8 & 6 & 60,00 & 90,00 & 30,00 \\
\hline 2 & 4 & 8 & 16 & 14 & 25,71 & 45,00 & 19,29 \\
\hline 3 & 4 & 12 & 24 & 22 & 16,36 & 30,00 & 13,64 \\
\hline 4 & 4 & 16 & 32 & 30 & 12,00 & 22,50 & 10,50 \\
\hline
\end{tabular}

The stator poles, $N_{\mathrm{S}}$, protrude at both ends and with the same length of the structural disk, now of a non-magnetic material, nailed to a hollow shaft. Two coils are wound in both opposite ends of the stator poles and are connected in series. A group of two stator poles, with their corresponding coils and connected between them in such a way that results in a single flux loop, which is closed through two rotors poles, forms a double electromagnet, $\mathrm{Z}$. The flux path is shown in the exploded view of the double rotor AFSRM in Fig.5.

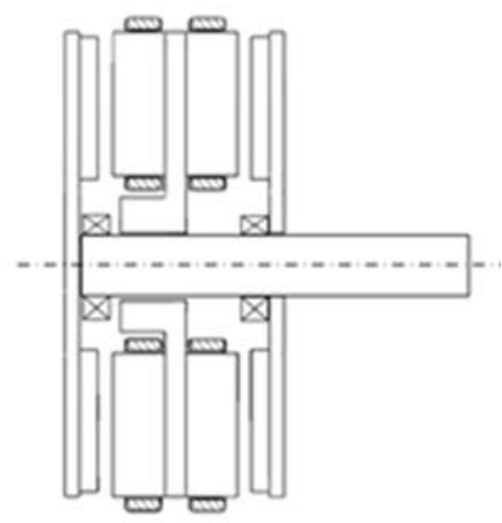

Fig.4. Double rotor AFSRM

The main stator and rotor dimension marks of the prototype are indicated in Fig. 6 and Fig.7 and their values are shown in Table III. The arrangement of the coils forming a double electromagnet and the series connection between the diametrically opposite double electromagnets that forms one phase are depicted in Fig. 8. Each coil of the four of a double electromagnet has 16 turns. One of the more challenging aspects of the axial flux switched reluctance machine is the construction of its magnetic circuit, given the difficulty of making it using laminations. Therefore, the ferromagnetic pieces of stator and the rotor of the proposed machine are preferably built using sintered pieces made of soft magnetic composites (SMC). SMC are iron powder particles separated with an electrically insulating layer. In this paper, the SMC used is Somaloy prototyping material.

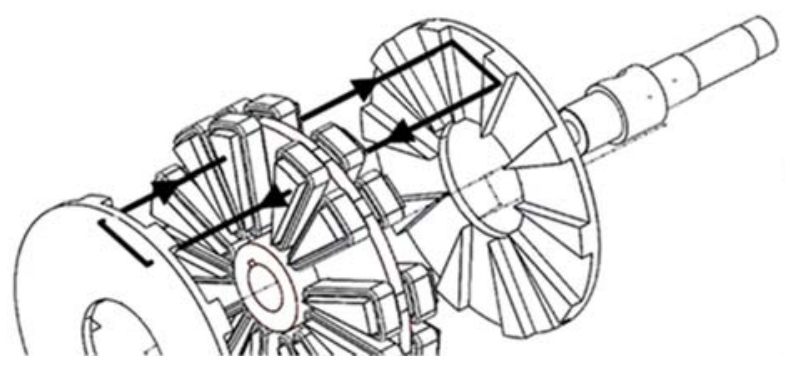

Fig.5. View of the flux path in one double electromagnet in a double rotor AFSRM

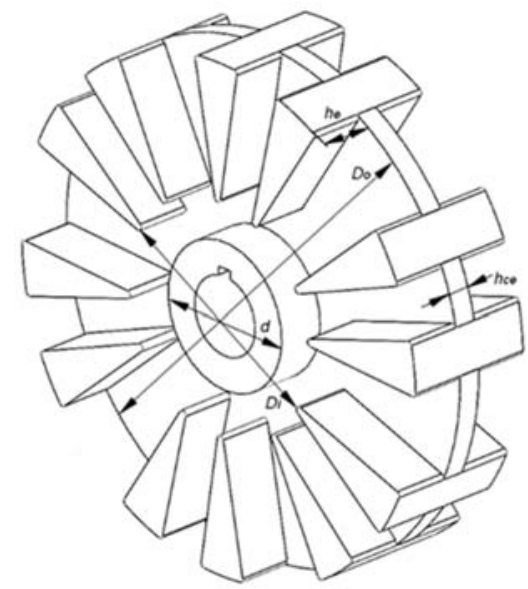

Fig.6. Stator view showing the main dimension marks

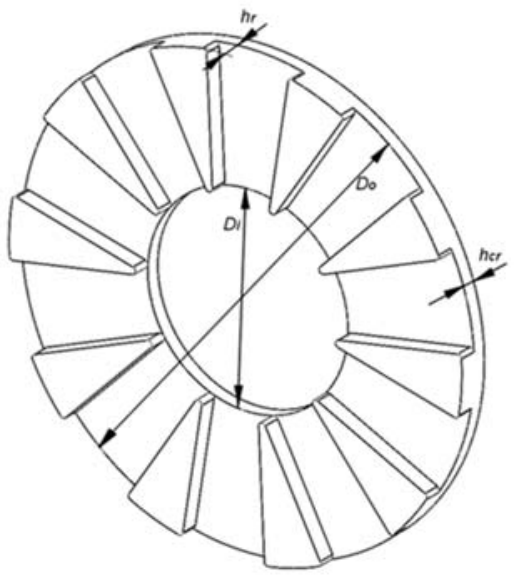

Fig.7. Rotor view showing the main dimension marks

Table III.- Main dimensions of the AFSRM prototype

\begin{tabular}{|c|c|}
\hline Dimensions & Values \\
\hline $\mathrm{D}_{\mathrm{o}}(\mathrm{mm})$ & 260 \\
\hline $\mathrm{D}_{\mathrm{i}}(\mathrm{mm})$ & 114.96 \\
\hline $\mathrm{d}(\mathrm{mm})$ & 75 \\
\hline $\mathrm{h}_{\mathrm{e}}(\mathrm{mm})$ & 28.9 \\
\hline $\mathrm{h}_{\mathrm{ce}}(\mathrm{mm})$ & 12 \\
\hline $\mathrm{h}_{\mathrm{r}}(\mathrm{mm})$ & 8 \\
\hline $\mathrm{h}_{\mathrm{cr}}(\mathrm{mm})$ & 10 \\
\hline
\end{tabular}




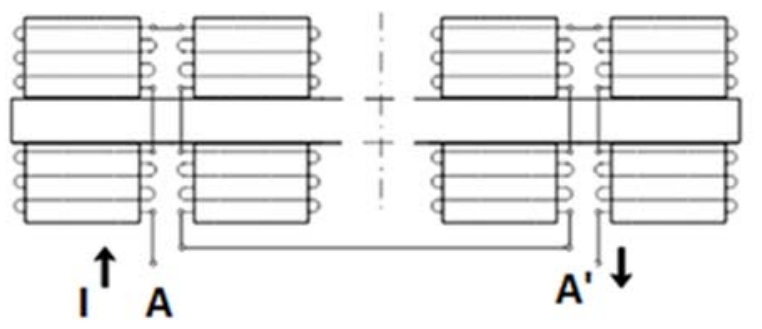

Fig. 8. Sketch of one phase of the AFSRM showing the series connection of the double electromagnets diametrically opposed and the coils arrangement

\section{Electromagnetic analysis of the double rotor AFSRM}

In a previous paper electromagnetic analysis of the double rotor AFSRM was performed using 2D FEM taking 2D planes of the machine geometry in several radiuses, transforming the axial-flux machine in a linear machine [9]. Thus the internal electromagnetic torque can be determined, in the case of considering the section corresponding to the average radius, by calculating the force of translation (x direction) of the resulting linear machine and multiplying by the mean radius. This procedure is fast and gives valuable information about the expected results of the motor but the values obtained are well above the measured. Nevertheless, the best way to model the double rotor AFSRM is using 3D FEM although is a cumbersome and high time consuming procedure. Flux 12.1 has been used for the electromagnetic analysis of this machine [10]. A picture of the grid is shown in Fig. 9 (420.588 nodes and 1.943.459 volume elements). In Fig. 10 a map of flux magnetic densities for a current of $100 \mathrm{~A}$ can be seen. In Fig. 11 and Fig. 12, the magnetization curves and the static torque curves of the double rotor AFSRM are represented. In order to obtain these curves a processing time of 681 hours (202 GB of disk space) was required in a desktop computer with a core I7 processor and with 64 GB RAM.

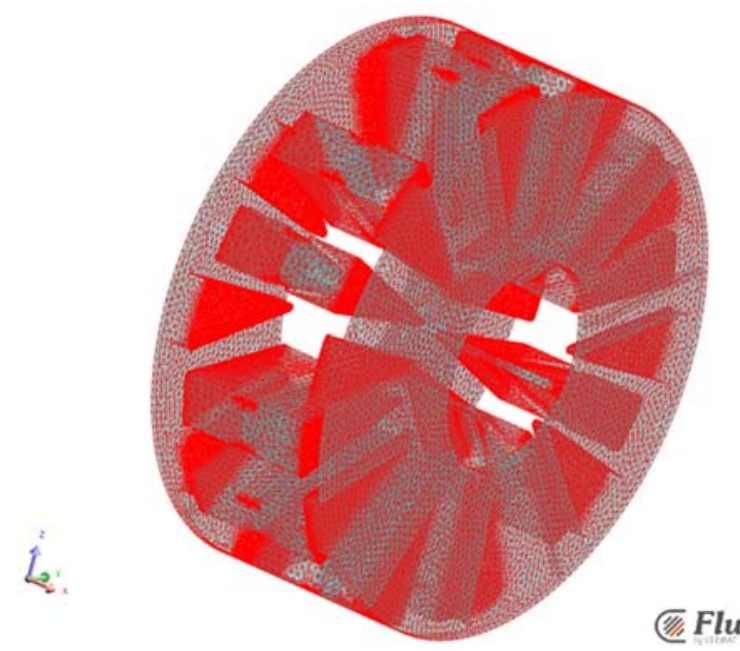

Fig. 9. View of the three dimensional grid of the double rotor AFSRM

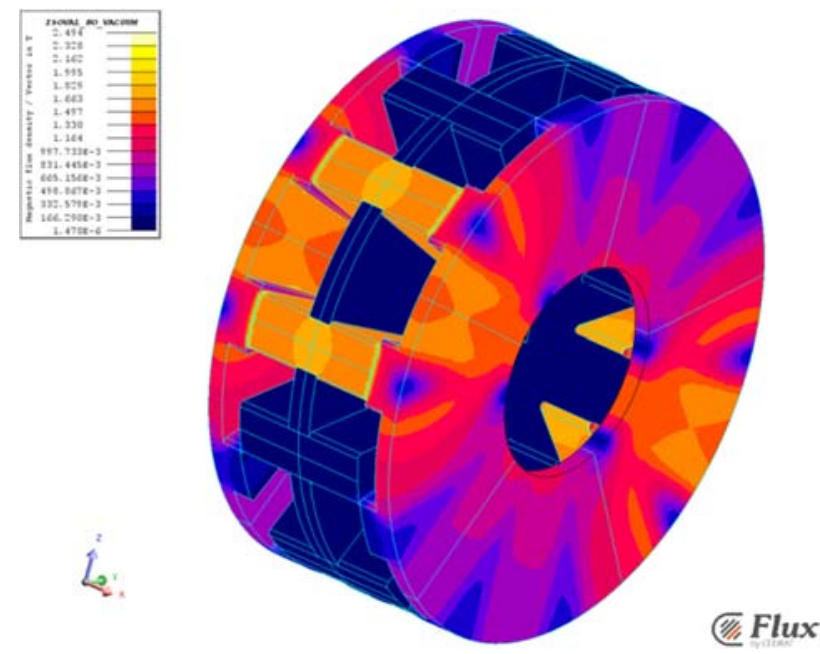

Fig. 10. Map of flux densities of the double rotor AFSRM for the aligned position for a current of $100 \mathrm{~A}$

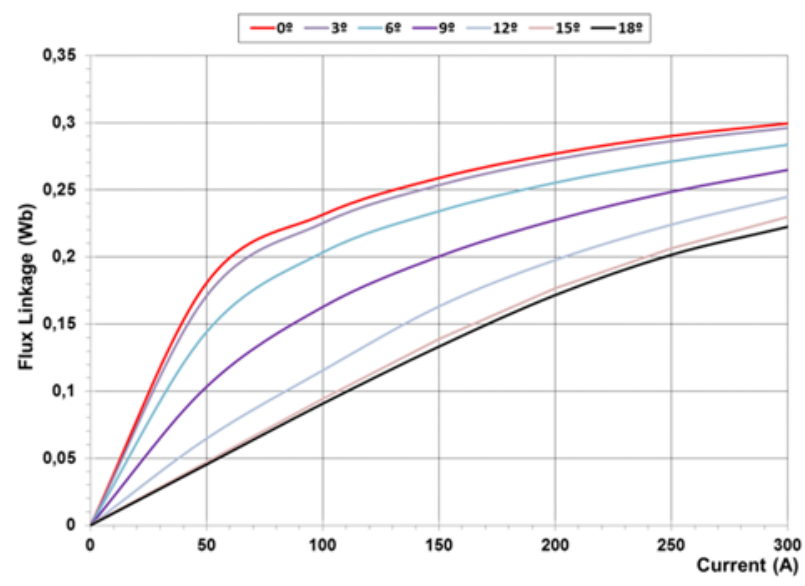

Fig.11.Magnetization curves of the double rotor AFSRM

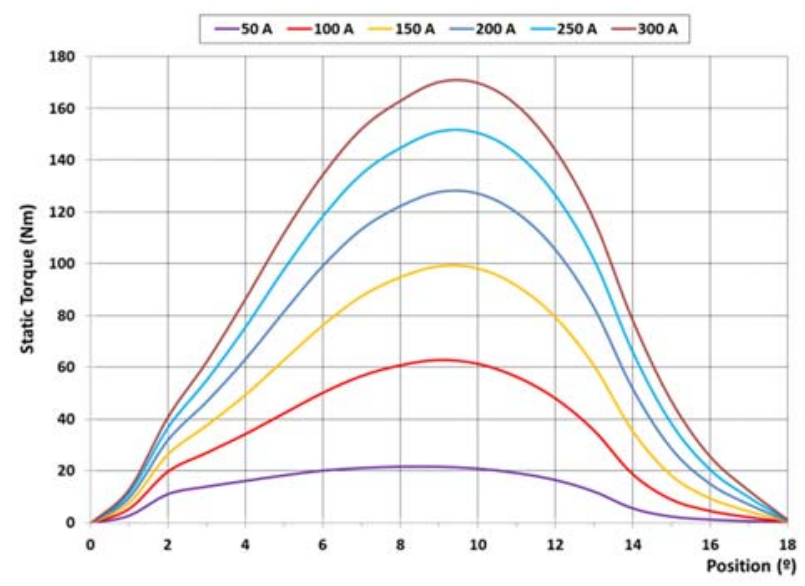

Fig.12. Static torque curves of the double rotor AFSRM

\section{Simulation of the double rotor AFSRM drive}

The proposed double AFSRM has been designed for the direct traction, without transmission, of an electric scooter with a total mass of $200 \mathrm{~kg}$ and wheels of $13^{\prime \prime}$. In order to fit into the wheel the external diameter of the 
motor is of $308 \mathrm{~mm}$ and the length of $116 \mathrm{~mm}$. The in wheel motor has to be able to provide a maximum torque of $170 \mathrm{Nm}$ between 0 to $20 \mathrm{~km} / \mathrm{h}(\sim 220 \mathrm{rpm})$ and a constant power of $4 \mathrm{~kW}$ between $20 \mathrm{~km} / \mathrm{h}(\sim 220 \mathrm{rpm})$ to $80 \mathrm{~km} / \mathrm{h}$ ( $900 \mathrm{rpm})$, the maximum speed is limited to $1200 \mathrm{rpm}$.

A block diagram of the drive, including the battery, the power converter, the control and the double AFSRM is shown in Fig. 13. The battery $\left(\mathrm{LiFePo}_{4}, \mathrm{LFP}\right)$ is of $48 / 72$ $\mathrm{V}$. The power converter is an asymmetric or classic converter for SRM. As a first control option the hysteresis control with variable turn-on and turn-off angles until 600 rpm and single pulse with variable turn -on turn-off angles for upper values of speed although the need for reduced torque ripple surely will require instantaneous direct torque control. The simulation was performed using Matlab-Simulink considering the results of the previous 3D FE analysis as was described in [9].

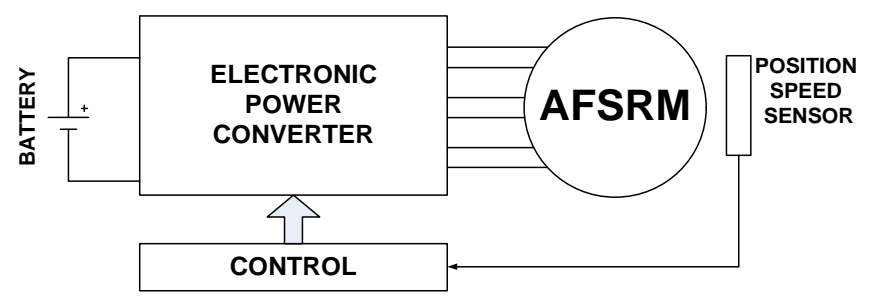

Fig.13. Block diagram of the double rotor AFSRM drive

The simulation results allow obtaining the waveforms of the electrical magnitudes of the drive, as well as the internal electromagnetic torque. Therefore is possible to predict the behaviour of the whole drive for the intended application. Thus, as it can be seen in fig. 14 the proposed drive is able to work inside the torque-speed envelope required for the E-scooter that has to propel, although some improvements in the machine design has to be done in order to match the values of torque at low speed (below $300 \mathrm{rpm})$.

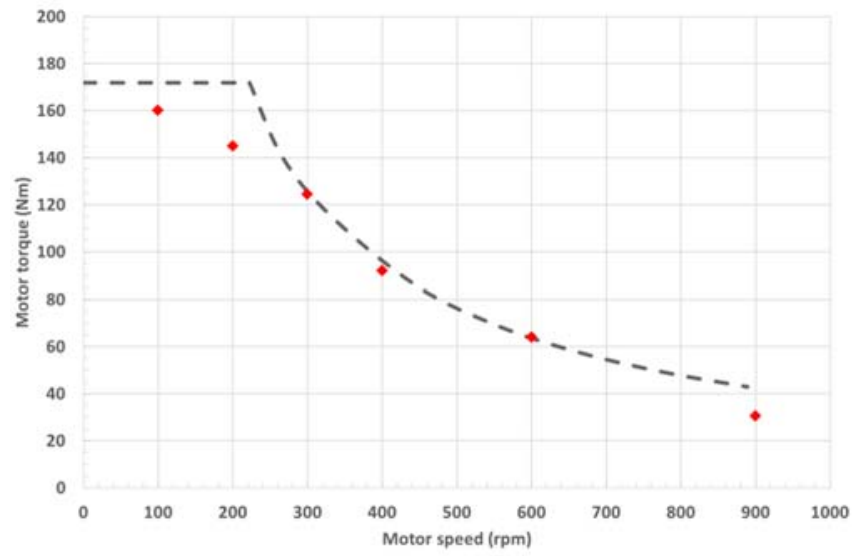

Fig.14. Comparison between the expected values of torque-speed envelope with the simulated values with 48 of battery voltage (in red)

\section{Conclusion}

In this paper, a novel double rotor new axial-flux switched reluctance motor for direct drive E-traction is presented.
This motor is constituted by a stator sandwiched by two rotors with a particular disposition of the stator and rotor poles in which the ferromagnetic parts are made of soft magnetic composites and has shorter flux paths with no flux reversal. The electromagnetic analysis is performed using 3D-FEA, The simulation of the whole drive, taking into account motor, power converter and control strategies is implemented in Matlab-Simulink using the results obtained from the electromagnetic analysis. Simulations show that the performances of the motor drive, match pretty well the requirements of the escooter.

\section{Acknowledgement}

This research was supported by Spanish Ministry of Economy and Competitiveness (DPI 2014-57086-R).

\section{References}

[1] L. E. Unnewehr and W.H. Koch. "An axial air-gap reluctance motor for variable speed applications," January/February 1974, IEEE Transactions on Power Apparatus and Systems.

[2] Arihara and K. Akatsu."Basic properties of an axialtype switched reluctance motor". IEEE Transactions on Industry Applications, Vol 49, No 1, January/February 2013.

[3] Murakami, H. Goto, O. Ichinokura. “A study about optimum stator pole design of axial-gap switched reluctance motor”. ICEM 2014, 2-5 September Berlin.

[4] R. Madhavan, B.G. Fernandes. "Axial flux segmented SRM with a higher number of rotor segments for electric vehicle". IEEE Transactions on Energy Conversion, Vol. 28, No 1, March 2013.

[5] Labak, N.C. Kar. "Designing and prototyping a novel five-phase pancake-shaped axial flux SRM for electric vehicle application through dynamic FEA incorporating flux-tube modeling”. IEEE Transactions on Industry Applications, Vol. 49, No 3, May/June 2013.

[6] Ma, R. Qu, J. Li. "Optimal design of an axial flux switched reluctance motor with grain oriented electrical steel". $18^{\text {th }}$ International Conference on Electrical Machines and Systems (ICEMs), 25-28 October 2015, Pattaya City, Thailand 2015.

[7] T. Kellerer, O. Radler, T. Sattel, S. Purfürst. “Axial type switched reluctance motor of soft magnetic composite". Innovative Small Drives and MicroMotor Systems, 19-20 September 2013, Nuremberg, Germany.

[8] T. Lambert, M. Biglarbegian, S. Mahmud. "A novel approach to the design of axial-flux switched reluctance motors”. Machines 2015, 3, 27-54; doi: 10:10.3390/machines3010027.

[9] P. Andrada, E. Martínez, B. Blanqué, M. Torrent, J.I. Perat, J.A. Sánchez. "New axial-flux switched reluctance motor for E-scooter". ESARS ITEC Toulouse, 2-4 November 2016.

[10] Flux 12.1. Altair 2016. 